\title{
Evaluation of Effective Factors and its Prevalence on Postpartum Depression Among Women in the City of Qom, Iran
}

\author{
Abbas Habibzadeh $^{1 *}$, Zohreh Habibzadeh ${ }^{2}$
}

\begin{abstract}
Objectives: The purpose of this study was to investigate the prevalence of factors affecting postpartum depression in women in the city of Qom, Iran.

Materials and Methods: This study was a survey research. The research population included all women who were within 4 weeks postpartum and referred to health centers in Qom. The sample consisted of 120 subjects who were selected by convenience sampling method. Edinburgh Postnatal Depression was the research tool. Once collected, the data were extracted and analyzed using SPSS software and $t$ test.

Results: Based on the findings, the prevalence of depression among the studied population in Qom was $40.83 \%$. Results showed that wanted or unwanted pregnancy has significant relation to depression while variables such as infants' gender, the nulliparous or pluriparous and mode of delivery did not significantly affect postpartum depression.

Conclusion: The results of the research showed that the rate of postpartum depression in the city of Qom is significantly higher than usual. In order to prevent the multiple consequences of the postpartum disorder in families and societies, active measures must be taken to put awareness- raising plans about the treatment of this disorder high on the agenda of health centers. It is also recommended to make strenuous efforts to hold workshops on the prevention of unwanted pregnancies which have made significant differences in this study.

Keywords: Gender, Infant, Postpartum depression, Delivery, Pregnancy
\end{abstract}

\section{Introduction}

Studies have shown that women suffer from depression more than men (1). Among different types of depression, postpartum depression is worthy of significant attention because it not only affects mother's health, but also adversely affects growth and psychological evolution of the newborn $(2,3)$. In many women, child birth is a stress-causing factor which is the stimulus for beginning of an acute depression or its recurrence (4). In fact, the period after the childbirth is the transitional period in which mother faces new roles, models, and relations that she has to adapt to (5). On the other hand, since the energy stored in a mother is lost during puerperium due to fatigue, drug effects, maternity duration, problems caused during the maternity process etc., the mother is subjected to emotional and psychological crises, including depression more than any other time (6).

Based on criteria described by the Diagnostic and Statistical Manual of Mental Disorders (fourth edition), postpartum depression is defined as the depression which occurs at the fourth week after the childbirth. This disorder is specified by signs and symptoms including depressed mood, lack of sense of satisfaction from life, irritability, amnesia, repeated dizziness, physical symptoms, ambivalence, negative feeling about the infant, inability to take care of the child, suicide thoughts (7), decreased self-confidence (8), hopelessness and incompetency, sense of guilt, fear and worthlessness (9).

According to the family systems theory, any factor that affects one member of a family and causes disorders in their performance within the family system, would inevitably also affect other members of the family, causing disorder in their behavior and performance (10). Prevalence of depression in husbands of the women suffering from this disorder is $5 \%-20 \%$ greater than others (11). Postpartum depression is one of the most important problems that threaten lives of mother, infant and their family (12). This disorder would result in decreased level of healthy relationship between mother and the infant (13), disorder in the growth of the infant $(14,15)$, decreased level of mother health, permanent depression in the women, problems and conflicts in the marital relationships $(16,17)$, increased obsessive-compulsive thought (18) and inability to carry out maternal and marital duties (19). Depressed mothers have lower sense of responsibility and responsiveness towards their infants and have complicated 
problems interacting with their child (20), which greatly threatens cognitive-psychological evolution of the child and might also cause ignorance and misbehavior in the child-care (21). Previous studies in Michigan University have verified the presence of relation between depression symptoms in mothers and hormonal-neural changes and disorder in adapting to various aspects including sleep, diet, emotion and attachment in the child (22).

Different levels of prevalence of postpartum depression have been reported by different studies $(8,14)$. It seems that the difference in the tools used for measuring the depression, method of selecting subjects for the study and demographic characteristics, as well as cultural differences can be the reason for different levels of prevalence of this health problem in various societies $(14,23)$. Level of prevalence of postpartum depression was reported as $10 \%-20 \%$ in the international studies (24). Studies in Iran reported the prevalence of postpartum depression to be within the range of $16 \%-31 \%$ (25-27).

Since prevalence of postpartum depression and its factors depend on cultural and social factors and there are various contradicting findings on the prevalence and etiology of the postpartum depression and also due to limited number of studies on this topic, especially in Qom city, therefore the purpose of this study was to investigate level of prevalence of postpartum depression and also to identify relationship between some of the factors with this disorder among women visiting health-medical centers in Qom city.

\section{Materials and Methods}

This study was a survey research which was conducted during 2014 in health-medical centers in Qom city. The subjects in the study included 120 women visiting health-medical centers near their house to follow up their postpartum care and have doctors examine their infants' profile, while 4 weeks had passed since their childbirth. The subjects were selected based on convenience sampling method. The method used to collect the data was such that after setting up the required coordination and receiving the certificate (the permit) from the health center and coordinating with the health-medical bases in Qom city, and explaining the question to clarify topic of the questions and to eliminate any ambiguity for the subjects, the questionnaires related to Edinburgh's postpartum depression test were given to the subjects and then the data were collected.

Edinburgh's questionnaire is simple method to screen the postpartum depression which is related to feelings of a mother during 7 days after the childbirth (12). Many studies have proved the efficiency of Edinburgh's questionnaire for identifying depressed women from the non-depressed ones (28). This questionnaire contains 10 multiple choice questions where a score of $0-3$ is allocated to each question of this questionnaire based on the answer provided by the subject; therefore, the minimum score was zero while the maximum score was 30 . In this study, the score greater than 12 was considered as depression (28-30). Validity of the Persian version of the questionnaire was verified in various studies conducted in Iran $(31,32)$. The data obtained from the Edinburgh's questionnaire was analyzed using SPSS software and statistical $t$ test method.

\section{Results}

In this study, 120 women with 4 weeks passing from their childbirth who had visited the health centers were investigated using Edinburgh's questionnaire. The results showed that prevalence of postpartum depression among women visiting health centers in Qom was 40.83\%, according to the depression score (non-depressed having a score smaller than 12 and depressed having a score greater than 12). Number of boys and girls were equally considered to be $60 ; 41.66 \%$ of the women whose infant was girl and $40 \%$ of the women whose infant was boy suffered from postpartum depression.

According to the Table 1, no statistical significant difference was observed between the infants' gender and prevalence of postpartum depression. Findings of the study indicated that $79 \%$ of women had their first childbirth, while $41 \%$ had their second or more childbirth; so, $40.5 \%$ of the nulliparous subjects and $41.6 \%$ of the pluriparous mothers had depression and according to $t$ test, no statistical significant difference was observed between these two groups in terms of postpartum depression. Among the women visiting the health centers, 76 women had natural childbirth, while 46 women underwent C-section (Cesarean) surgery. Also $39.13 \%$ of women who had undergone C-section and $41.89 \%$ of the women with natural childbirth had postpartum depression. According to the table, the difference was not statistically significant. Also, the results showed that half of the women who had unwanted pregnancy suffered from postpartum depression; while, women with planned pregnancy had lower rate (38.04\%) of postpartum depression which marked a statistically significant difference using statistical tests. It can be claimed that unwanted and unplanned pregnancy was among factors that increased the possibility of suffering from postpartum depression among women visiting health-medical centers in Qom city.

\section{Discussion}

Postpartum depression is a common social debilitating disorder (33). Prevalence of postpartum depression is closely related to cultural and social factors (34) and for this reason, different prevalence levels have been reported in different countries and races. Various studied conducted in different countries reported the prevalence of postpartum depression to be within the range of 10\%-20\% (35-37), 10\%-15\% (38) and 20\%-28\% (15). In the present study, prevalence of postpartum depression was reported to be $40.83 \%$ in Qom city which is greater than other studies conducted in Iran, which reported prevalence of postpartum depression to be within the range 16\%-31\% (2527). However, its prevalence was smaller than that reported by Salmalian et al (39) which was equal to $64.6 \%$ and was approximately similar to results of study by Zangeneh 
Table 1. $T$ Test Outcomes

\begin{tabular}{|c|c|c|c|c|c|c|c|c|}
\hline Variables & & $\mathrm{n}$ & $\begin{array}{c}\text { Non-depressed } \\
\text { No. (\%) }\end{array}$ & $\begin{array}{c}\text { Depressed } \\
\text { No. (\%) }\end{array}$ & Mean & SD & DF & $\alpha$ \\
\hline \multirow[t]{2}{*}{ Infant's gender } & Female & 60 & 35 (58.33) & $25(41.66)$ & 11.50 & 5.89 & 118 & 0.095 \\
\hline & Male & 60 & $36(60)$ & $24(40)$ & 11.41 & 6.12 & & \\
\hline \multirow[t]{2}{*}{ No. of delivery } & Nulliparous & 79 & 47 (59.49) & $32(40.50)$ & 11.30 & 5.05 & 118 & 0.065 \\
\hline & Pluriparous & 41 & $24(58.53)$ & $17(41.46)$ & 11.87 & 7.11 & & \\
\hline \multirow[t]{2}{*}{ Mode of delivery } & Cesarean & 46 & $28(60.86)$ & $18(39.13)$ & 11.87 & 6.45 & 118 & 0.078 \\
\hline & Natural & 74 & $43(58.10)$ & 31 (41.89) & 11.12 & 5.66 & & \\
\hline \multirow[t]{2}{*}{ Type of pregnancy } & Wanted & 92 & 57 (61.95) & 35 (38.04) & 10.80 & 5.54 & 118 & 0.018 \\
\hline & Unwanted & 28 & $14(50)$ & $14(50)$ & 13.60 & 6.13 & & \\
\hline
\end{tabular}

et al (40) in which the prevalence was reported as $40.7 \%$. According to the results in this study, no significant difference was observed between nulliparous and pluriparous mothers. This result was in agreement with the results of study by Carroll et al (41). Gotlib et al (42) also examined a group of 360 pregnant women during their pregnancy and after the childbirth and came to this conclusion that large number of childbirth did not have considerable effect on postpartum depression. On the contrary, in a study by Zinga et al, the possibility of occurrence of postpartum depression in nulliparous women was greater than that in pluriparous women which can be related to transition to motherhood stage and low level of self-confidence of nulliparous mothers in meeting the needs of the infant (43). Also in another study which was conducted in Kerman, Ghaffarinejad et al concluded that depression rate was greater among nulliparous mothers (44).

Results in a study by Hung et al showed that there was a significant relation between number of childbirth and the postpartum depression, such that increase in the number of childbirth increases the possibility of depression (45). It can be stated that when the number of children increases, the mother would have less time to take rest and have entertainment. Therefore, this would result in fatigue (tiredness) in the mother which makes her susceptible to postpartum depression (45). Johnstone et al also found a relationship between pluriparity and postpartum depression (46). In a study by Wang et al, a significant relation was found between childbirth and depression (6).

According to the results obtained from this study, there was no significant difference in terms of prevalence of depression between women with and without planned pregnancy which was in agreement with the results of previous studies $(44,47,48)$ as well as with the opinion by Kaplan and Sadock (7). According to McCoy et al (49) and Nakku et al (50), pathologic stresses in human are known for a natural pregnancy, while regarding the unwanted pregnancy causes multiple problems for the mother, because unwanted pregnancy would result in duality in accepting or denying the infant, causing many psychological disorders for the mother $(49,50)$.

An unwanted pregnancy can cause physical and psychological problems for the mother, therefore threatening her health; also, the woman's negative perspective towards the pregnancy is important (12). Dennis et al believes that un- expected pregnancy can cause duality towards infant and the infant's denial, both of which can increase the possibility of occurrence of depression in the person. Dennis et al observed that, individuals who decide to have child with previous plans would have a life with more social and economic balance (38). Beck and Gable also reported that there was a significant relationship between preparedness to accept responsibility of an infant and postpartum depression (51).

Rahmani et al found in their studies that there was a significant relationship between husbands's feeling about the recent childbirth and postpartum depression. It seems that the husband also must also be equally prepared to accept the responsibility of a new child. When the husband is happy of the new family member, it would decrease wife's stress and anxiety and also provide her emotional and psychological needs (52).

According to the results obtained in this study, level of postpartum depression in women whose infant was boy was not significantly different than that in the women whose infant was girl. This result was in agreement with Zangeneh et al (40) and Wang et al (6). However, this was not in agreement with the study by Hosseini et al in Kermanshah (47), Ghaffarinejad et al (44) and Khodadadi et al (25) which could result from the families' cultural perspectives where a special attention is given to boys as a supporter in the family and work responsibilities. Chee et al (53) conducted a study on 7224 women who gave birth in Singapore. Results of their study showed that there was a weak relationship between depression during the pregnancy and the child being girl.

In this study, two groups including natural birth and C-section surgery were compared in terms of prevalence of postpartum depression. Results of the study showed that there was no significant difference in terms of depression prevalence between women with natural childbirth and women who had C-section surgery which was in agreement with results of study by Hosseini et al (47), and was the opposite of results reported in studies by Dolatian et al (31), Boyee and Todd (12), Adewuya et al (54), Ukpong and Owolabi (55) and Hannah et al (56). Results in these studies showed that childbirth with C-section surgery increased the possibility of depression. While results of study by Chaaya et al (57) showed that depression is lower among mothers with C-section surgery than mothers with 
natural childbirth. Carter et al (58) also investigated the results of depression and postpartum depression reported in 24 studies; there was a relationship between these two factors in 5 articles, while in 15 studies, no relationship was observed between the two factors. Mortality rate among mothers with C-section surgery was 2 to 5 times greater than mothers with natural childbirth, with the former also having more severe and more common physical disorders. Garel et al came to this conclusion that during one year after the childbirth, women with C-section surgery suffer greater physical and psychological symptoms than mothers with natural childbirth (59). So far, limited studies have been conducted regarding psychological disorders of C-section surgery and other midwifery surgeries. Clement (30) investigated other studies by other researchers and stated that women who gave birth with C-section surgery had lower satisfaction with their delivery in 18 articles, while 11 studies reported that women with C-section surgery had depression more than mothers with natural childbirth. Meanwhile, no significant difference was observed between the two groups in terms of occurrence of depression in 9 other studies. Results also showed that the negative feeling the mothers experience after the C-section surgery included feeling of devastation and loss, disturbed communication with the infant, change of personality and personality disorder, feeling of desecration, anger with the personnel who are taking care of the mother and fear from death (30). Other factors which seem to place the mothers with C-section surgery in greater risk of depression included mother sees her infant at a later time after the delivery, the husband cannot be present beside his wife to support her during the C-section surgery, urgent C-section surgery is an unexpectable and stressful events, and mother and infant might have more problems after the C-section (60).

\section{Conclusion}

Investigating psychological diseases after the childbirth is important from three perspectives; First, its beginning is predictable and occurs at the time of childbirth. Second, this disorder causes severe psychological pressure in this period of the wife's life which adversely affects specific duties and her adaptation process. Third, the mother's inability to communicate with the infant has unfortunate consequences on the growth of the cognitive, social, cultural and emotional capabilities of the child.

Since the first steps in the growth of the child is established by the mothers, only the physically and psychologically healthy mothers can take more effective steps in growing a healthy child. Therefore, it is important to pay attention to the psychological condition of the mother and understand the effective factors. The risky factors on postpartum depression can be determined after the childbirth. Postpartum depression has been repeatedly ignored by the patients and the person who takes care of her and only a limited number of these cases have been identified by health and medical workers.

It is suggested to hold workshops for couples about preg- nancy and psychological health education for mothers, before and after the childbirth, and to provide information about symptoms of postpartum depression among women of that region and to compare the effective factors to prevent and control this disease. It is also necessary to provide intervention after the childbirth and effective help to improve the psychological health among women in Qom by controlling factors effective on postpartum depression to provide the primary prevention.

\section{Ethical issues}

All the participants of this research project signed an informed consent for participation and cooperation.

\section{Conflict of interests}

The authors declare no conflict of interests.

\section{Financial support}

The authors declare no financial and material supports in this project.

\section{Acknowledgments}

The authors declare that there is no acknowledgement

\section{References}

1. Michaud CM, Murray CJ, Bloom BR. Burden of disease-implications for future research. JAMA. 2001;285(5):535-539. doi:10.1001/jama.285.5.535.

2. Miller LJ. Postpartum depression. JAMA. 2002;287(6):762-5. doi:10.1001/jama.287.6.762.

3. Bloch M, Rotenberg N, Koren D, Klein E. Risk factors for early postpartum depressive symptoms. Gen Hosp Psychiatry. 2006;28(1):3-8. doi:10.1016/j. genhosppsych.2005.08.006.

4. Robertson E, Grace S, Wallington T, Stewart DE. Antenatal risk factors for postpartum depression: a synthesis of recent literature. Gen Hosp Psychiatry. 2004;26(4):289-295. doi:10.1016/j. genhosppsych.2004.02.006.

5. Stocky A, Lynch J. Acute psychiatric disturbance in pregnancy and the puerperium. Baillieres Best Pract Res Clin Obstet Gynaecol. 2000;14(1):73-87. doi:10.1053/beog.1999.0064.

6. Wang SY, Jiang XY, Jan WC, Chen CH. A comparative study of postnatal depression and its predictors in Taiwan and mainland China. Am J Obstet Gynecol. 2003;189(5):1407-1412.doi:10.1067/S00029378(03)00673-2.

7. Kaplan HI, Sadock BJ. Synopsis of psychiatry: Behavioral sciences clinical psychiatry. Williams \& Wilkins Co; 1988.

8. Tannous L, Gigante LP, Fuchs SC, Busnello ED. Postnatal depression in Southern Brazil: prevalence and its demographic and socioeconomic determinants. BMC Psychiatry. 2008;8(1):1. doi:10.1186/1471-244X-8-1.

9. Millis JB, Kornblith PR. Fragile beginnings: identification and treatment of postpartum disorders. 
Health Soc Work. 1992;17(3):192-199. doi:10.1093/ hsw/17.3.192.

10. Leonard LG. Depression and anxiety disorders during multiple pregnancy and parenthood. J Obstet Gynecol Neonatal Nurs. 1998;27(3):329-337. doi: 10.1111/j.1552-6909.1998.tb02656.x.

11. Goodman JH. Paternal postpartum depression, its relationship to maternal postpartum depression, and implications for family health. J Adv Nurs. 2004;45(1):26-35. doi:10.1046/j.13652648.2003.02857.x.

12. Boyee $\mathrm{P}$, Todd A. Increased risk of postnatal depression after emergency Cesarean section. Med J Aust. 1992;156:172-174.

13. Santos IS, Matijasevich A, Tavares BF, da Cruz Lima AC, Riegel RE, Lopes BC. Comparing validity of Edinburgh scale and SRQ20 in screening for postpartum depression. Clin Pract Epidemiol Ment Health. 2007;3(1):18. doi:10.1186/1745-0179-3-18.

14. Moraes IG, Pinheiro RT, Silva RA, Horta BL, Sousa PL, Faria AD. Prevalence of postpartum depression and associated factors. Revista de Saúde Pública. 2006;40(1):65-70. doi:10.1590/S003489102006000100011.

15. Póo FA, Espejo SC, Godoy PC, Gualda de la CM, Hernández OT, Pérez HC. Prevalence and risk factors associated with postpartum depression in puerperal women consulting in primary care. Revista Medica De Chile. 2008;136(1):44-52.

16. Galler JR, Harrison RH, Ramsey F, Forde V, Butler SC. Maternal depressive symptoms affect infant cognitive development in Barbados. J Child Psychol Psychiatry. 2000;41(06):747-757.

17. Martins C, Gaffan EA. Effects of early maternal depression on patterns of infant-mother attachment: A meta-analytic investigation. J Child Psychol Psychiatry. 2000;41(06):737-746.

18. Noble RE. Depression in women. Metabolism. 2005;54(5):49-52. doi:10.1016/j.metabol.2005.01.014.

19. Lowdermilk DL, Perry SE, Cashion MC, Alden KR. Study Guide For Maternity \& Women's Health Care. Elsevier Health Sciences; 2014.

20. Posmontier B. Sleep quality in women with and without postpartum depression. J Obstet Gynecol Neonatal Nurs. 2008;37(6):722-737. doi:10.1111/ j.1552-6909.2008.00298.x.

21. Vesga-Lopez O, Blanco C, Keyes K, Olfson M, Grant BF, Hasin DS. Psychiatric disorders in pregnant and postpartum women in the United States. Arch Gen Psychiatry. 2008;65(7):805-815. doi:10.1001/ archpsyc.65.7.805.

22. Marcus SM. Depression during pregnancy: rates, risks and consequences--Motherisk Update 2008. Can J Clin Pharmacol. 2008; 16(1):e15-e22.

23. Salary P, Banafshe E, Hebrani P, Nooghabi JJ. On the relationship between maternal fatigue and postpartum depression. J Fundamentals Mental Health. 2010; 11(4):302-311. [Persian].
24. Sadock BJ, Sadock VA, Kaplan HI. Kaplan and Sadock's Comprehensive Textbook of Psychiatry. USA: Lippincott Williams \& Wilkins; 2005:14411503.

25. Khodadadi N, Mahmoodi H, Mirhagjoo N. Postpartum depression relationship with some psychosocial effects in mothers. J Ardabil Univ Med Sci. 2008;8(2):142-148. [Persian]

26. Azimi Lolati H, Danesh MM, Hosseini SH, Khalilian AR, Zarghami M. Postpartum depression in clients at health care centers in Sari Iranian. Iran J Psychiatry Clin Psychol. 2005;11(1):31-42.

27. Bahadoran P, Mohamad Alibeigi N. Stress and anxiety in pregnancy. Iranian J Nurs Midwifery Res. 2010;10:2.

28. Cox JL, Holden JM, Sagovsky R. Detection of postnatal depression. Development of the 10-item Edinburgh Postnatal Depression Scale. Br J Psychiatry. 1987;150(6):782-786. doi:10.1192/bjp.150.6.782.

29. Eberhard-Gran M, Eskild A, Tambs K, Opjordsmoen S, Ove Samuelsen S. Review of validation studies of the Edinburgh Postnatal Depression Scale. Acta Psychiatr Scand. 2001;104(4):243-249. doi:10.1111/ j.1600-0447.2001.00187.x.

30. Clement S. Psychological aspects of caesarean section. Best Practice Res Clin Obstet Gynaecol. 2001;15(1):109-126. doi:10.1053/beog.2000.0152.

31. Dolatian M, Maziar P, Alavi Majd H, Yazdjerdi M. The relationship between mode of delivery and postpartum depression. J Reprod Infertil. 2006;7:260268.

32. Khorramirad A, Lotfi MM, Bidgoli AS. Prevalence of postpartum depression and related factors in Qom. Pajoohandeh J. 2010;15(2):62-66. [Persian].

33. Murray D, Cox J, Chapman G, Jones P. Childbirth: life event or start of a long-term difficulty? Further data from the Stoke-on-Trent controlled study of postnatal depression. Br J Psychiatry. 1995;166(5):595-600. doi: 10.1192/bjp.166.5.595.

34. Reid V, Meadows-Oliver M. Postpartum depression in adolescent mothers: an integrative review of the literature. J Pediatric Health Care. 2007;21(5):289298. doi:10.1016/j.pedhc.2006.05.010

35. Beck CT, Gable RK. Postpartum depression screening scale: development and psychometric testing. Nurs Res 2000;49(5):272-282.

36. Glasser S, Barell V, Boyko V, et al. Postpartum depression in an Israeli cohort: demographic, psychosocial and medical risk if actors. J Psychosomatic Obstet Gynecol. 2000;21(2):99-108. doi:10.3109/01674820009075615.

37. Xie RH, He G, Koszycki D, Walker M, Wen SW. Prenatal social support, postnatal social support, and postpartum depression. Ann Epidemiol. 2009;19(9):637-643. doi:10.1016/j. annepidem.2009.03.008.

38. Dennis CL, Janssen PA, Singer J. Identifying women at-risk for postpartum depression in the 
immediate postpartum period. Acta Psychiatr Scand. 2004;110(5):338-346. doi:10.1111/j.16000447.2004.00337.x.

39. Salmalian H, Nasiri AF, Kheyrkhah F. Prevalence of pre and postpartum depression symptoms and some related factors (Babol; 2006-2007). J Babol Univ Med Sci. 2008;10(3):67-75.

40. Zangeneh M, Shamsalizadeh N, Kaamravamanesh M, Rezai M, Pormehr S. Postpartum depression and its relation to baby gender and unplanned pregnancy. Scientific J Kurdistan Univ Med Sci. 2009;14(2):6571.

41. Carroll JC, Reid AJ, Biringer A, et al. Effectiveness of the antenatal psychosocial health assessment (ALPHA) form in detecting psychosocial concerns: a randomized controlled trial. CMAJ. 2005;173(3):253259. doi:10.1503/cmaj.1040610.

42. Gotlib IH, Whiffen VE, Wallace PM, Mount JH. Prospective investigation of postpartum depression: factors involved in onset and recovery. J Abnorm Psychol. 1991;100(2):122. doi:10.1037/0021843X.100.2.122.

43. Zinga D, Phillips SD, Born L. Postpartum depression: we know the risks, can it be prevented? Rev Bras Psiquiatr. 2005;27(suppl 2):s56-s64. doi:10.1590/ S1516-44462005000600005.

44. Ghaffarinejad A, Khobyyari F, Pouya F. Prevalence of postpartum depression in Kerman. Iran J Psych Clin Psychol (Andishe Va Raftar). 2007;17(18):24-29. [Persian].

45. Hung CH, Lin CJ, Stocker J, Yu CY. Predictors of postpartum stress. J Clin Nurs. 2011;20(5-6):666-674.

46. Johnstone SJ, Boyce PM, Hickey AR, Morris-Yates AD, Harris MG. Obstetric risk factors for postnatal depression in urban and rural community samples. Aust N Z J Psychiatry. 2001;35(1):69-74. doi:10.1046/ j.1440-1614.2001.00862.x.

47. Hosseini SH, Naghibi AA, Khademlou M. Post partum depression and its relationship with some related factors. J Babol Univ Med Sci. 2008;10(2):7681. [Persian].

48. Iranfar S, Shakeri J, Ranjbar M, Nazhad Jafar P, Razaie M. Is unintended pregnancy a risk factor for depression in Iranian women? East Mediterr Health J. 2005;11(4):618-624.

49. McCoy SJ, Beal JM, Shipman SB, Payton ME, Watson GH. Risk factors for postpartum depression: a retrospective investigation at 4 -weeks postnatal and a review of the literature. J Am Osteopath Assoc. 2006;106(4):193-198.

50. Nakku J, Nakasi G, Mirembe F. Postpartum major depression at six weeks in primary health care: prevalence and associated factors. Afr Health Sci. 2007;6(4):207-214.

51. Beck CT. Predictors of postpartum depression: an update. Nurs Res. 2001;50(5):275-285.

52. Rahmani F, Seyedfatemi N, Asadollahi M, Seyedrasooli A. Predisposing factors of postpartum depression. Iran J Nurs. 2011;24(72):78-87.

53. Chee CY, Lee DT, Chong Y, Tan L, Ng T, Fones CS. Confinement and other psychosocial factors in perinatal depression: a transcultural study in Singapore. J Affect Disord. 2005;89(1-3):157-166. doi:10.1016/j.jad.2005.09.004.

54. Adewuya AO, Fatoye FO, Ola BA, Ijaodola OR, Ibigbami SM. Sociodemographic and obstetric risk factors for postpartum depressive symptoms in Nigerian women. J Psychiatr Pract. 2005;11(5):353358.

55. Ukpong D, Owolabi A. Postpartum emotional distress: a controlled study of Nigerian women after caesarean childbirth. J Obstet Gynecol. 2006;26(2):127-129. doi: 10.1080/01443610500443386.

56. Hannah P, Adams D, Lee A, Glover V, Sandler M. Links between early post-partum mood and postnatal depression. Br J Psychiatry. 1992;160(6):777780. doi: 10.1192/bjp.160.6.777.

57. Chaaya M, Campbell O, El Kak F, Shaar D, Harb H, Kaddour A. Postpartum depression: prevalence and determinants in Lebanon. Arch Womens Ment Health. 2002;5(2):65-72. doi: 10.1007/s00737-0020140-8.

58. Carter FA, Frampton CM, Mulder RT. Cesarean section and postpartum depression: a review of the evidence examining the link. Psychosom Med. 2006;68(2):321330. doi:10.1097/01.psy.0000204787.83768.0c.

59. Garel M, Lelong N, Kaminski M. Follow-up study of psychological consequences of caesarean childbirth. Early Hum Dev. 1988;16(2-3):271-282. doi:10.1016/0378-3782(88)90108-9.

60. Ryding EL, Wijma K, Wijma B. Experiences of emergency cesarean section: a phenomenological study of 53 women. Birth. 1998;25(4):246-251. doi:10.1046/j.1523-536X.1998.00246.x.

Copyright $(2016$ The Author(s); This is an open-access article distributed under the terms of the Creative Commons Attribution License (http://creativecommons.org/licenses/by/4.0), which permits unrestricted use, distribution, and reproduction in any medium, provided the original work is properly cited. 